\title{
Records of the tsunami induced by the 2010 Chilean earthquake from Xiaoqushan seafloor observatory in the East China Sea
}

\author{
ZHANG YanWei*, FAN DaiDu \& XU HuiPing \\ State Key Laboratory of Marine Geology, Tongji University, Shanghai 200092, China
}

Received December 29, 2010; accepted June 3, 2011

\begin{abstract}
Sea-level variation can be induced by periodic tides, stochastic wind, air pressure, and swell. Larger sea-level variation has the potential to cause coastal disasters. In this paper, real-time continuous data obtained by the Xiaoqushan seafloor observatory in the East China Sea were analyzed employing frequency power spectral and tidal harmonic methods to extract the major components and periodicities of sea-level change. The sea-level anomaly (sla) was calculated by subtracting the tidal components from the observed sea level data. In the study period, the correlation between sla and the local north-south wind speed was high with a correlation coefficient of 0.65 at the $95 \%$ confidence level. The local wind-induced sea-level anomaly (sla wind $_{\text {) }}$ was therefore computed through linear fitting. Although sla $\mathrm{w}_{\text {wind }}$ is one of the main components of sla, the residual sea-level anomaly (sla $\left.\mathrm{a}_{\text {residual }}\right)$ obtained by subtracting sla $_{\text {wind }}$ from sla is not zero, suggesting that there are other factors besides wind. Detailed analysis of the sea-level data at the time of the 8.8-magnitude Chilean earthquake on February 27, 2010 showed a peak sla residual $_{\text {value of } 0.48 \mathrm{~m}}$ at around 15:00 on February 28, which was highly coincident with the tsunami arrival time forecast by the Pacific Tsunami Warning Center. The peak sla ${ }_{\text {residual }}$ event is therefore linked with the tsunami induced by the 2010 Chilean earthquake. This is the first time that a tsunami has been detected using real-time continuous data recorded by a seafloor observatory in the sea off China. Such observations are expected to improve tsunami forecast models and promote the development of a tsunami warning system and a seafloor observatory network in the East China Sea.
\end{abstract}

sea-level anomaly, seafloor observatory, tide, wind, Chilean earthquake

Citation: Zhang Y W, Fan D D, Xu H P. Records of the tsunami induced by the 2010 Chilean earthquake from Xiaoqushan seafloor observatory in the East China Sea. Chinese Sci Bull, 2011, 56: 2957-2965, doi: 10.1007/s11434-011-4624-7

Sea level varies greatly, and its variations on a short time scale can be driven by the tide with notable periodicity. Other stochastic components are potentially linked with wind or swells [1,2]. The abrupt rise in sea level due to a storm surge or tsunami has high potential for disaster and is considered a concern by coastal countries [3]. Twenty-six Pacific countries and regions with high vulnerability to tsunami strikes established the Pacific Tsunami Warning Center with headquarters in Hawaii in the summer of 1965, with China being one of the earliest members.

It was usually accepted that there are seldom tsunamis in marginal seas owing to the shallow and broad continental shelf [4], and this seems to be true in the past for China

*Corresponding author (email: ywzhang@ @tongji.edu.cn) according to limited documentary records [5-9]. However, this view has been called into serious question after the tremendous tsunami disaster resulting from the Indonesian earthquake on December 26, 2004, in which the death toll was more than 230000 and numerous coastal towns were destroyed [10]. The tremendous losses during the event were due to not only the formidable tsunami produced by the abnormally strong earthquake but also the absence of a tsunami warning system, a lack of coastal infrastructure, and little past experience in the region to draw from. Since then, coastal countries have paid more attention to and provided larger budgets for the development and upgrade of a tsunami warning system.

The low-lying southeast coast of China is the most densely populated and economically most developed region 
in the country, and tremendous losses are thus expected if it is stuck by a large tsunami. As a result, improving the tsunami warning system is crucial. Scientists in China have recently undertaken the task to develop a tsunami propagation model [6,7], and the State Ocean Administration of the People's Republic of China has set about to construct a tsunami warning system offshore [9]. In this paper, sea-level data obtained from the Xiaoqushan seafloor observatory and sea surface temperature, salinity and wind obtained from a nearby weather station are analyzed to obtain residual sea-level anomalies by extracting tidal and wind-induced components. We focus on the record of the tsunami induced by the Chilean earthquake that occurred on February 27, 2010 [3] to detect the maximum sea-level variations and provide a theoretical basis for the construction a future seafloor observatory and tsunami warning system [11].

\section{Xiaoqushan seafloor observatory and data}

The experimental station of the East China Sea seafloor observatory was deployed near Xiaoqushan Island at the mouth of Hangzhou Bay $\left(30.5^{\circ} \mathrm{N}, 122.2^{\circ} \mathrm{E}\right.$, Figure 1). The Xiaoqushan seafloor observatory came into operation on April 20, 2009. Real-time data are transmitted to servers that were set up onshore. To date, the Xiaoqushan seafloor observatory has been equipped with one $1200 \mathrm{kHz}$ acoustic Doppler current profiler (ADCP) and one conductivitytemperature-depth (CTD) detector, which were deployed about $0.8 \mathrm{~m}$ above the seafloor. The ADCP was set looking vertically upward with $0.25 \mathrm{~m}$ bins and a 1-min sampling interval, and this ADCP was replaced with another 1200 $\mathrm{kHz}$ ADCP with the same configuration but with $0.4 \mathrm{~m}$ bins when the first was dragged away probably by fishernen in

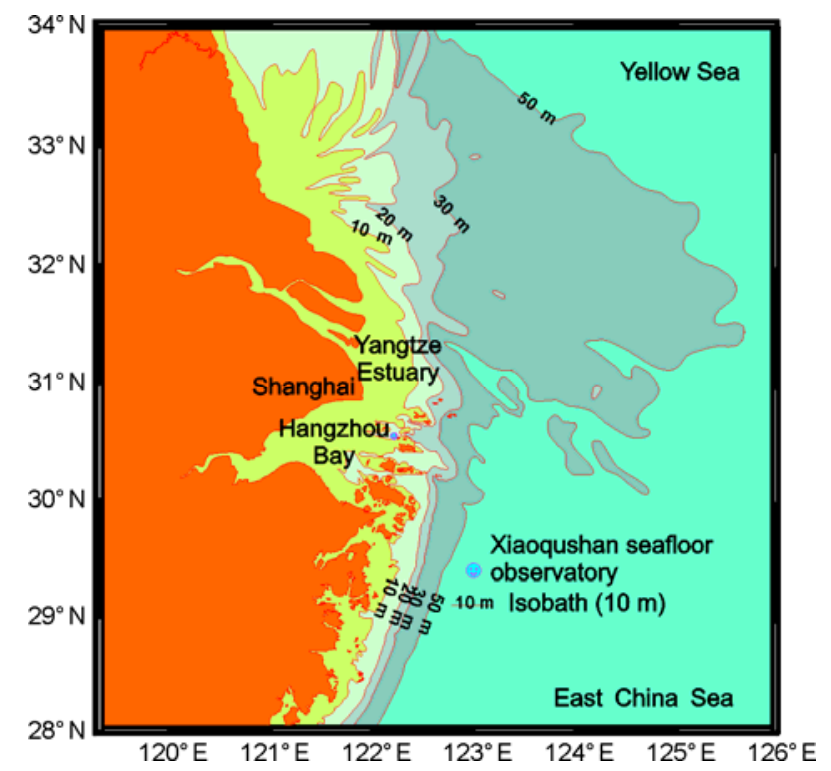

Figure 1 Topography around the Xiaoqushan seafloor observatory (the blue dark circle), with isobaths labeled.
August 2009; i.e. the first ADCP was in operation from April to August 2009 and the second has been in operation since October 2009. The data used in this paper cover the periods from April to August 2009 and October 2009 to August 2010. The second ADCP is still in operation at the time of writing in April 2011. The CTD detector was set to measure the sea-water temperature, salinity and turbidity near the seafloor every $1 \mathrm{~min}$. Details on the Xiaoqushan seafloor observatory can be found in a related paper written by Xu et al. [12].

Besides the data obtained by the ADCP and CTD detector, sea-surface data and weather measurements were collected from the Xiaoqushan weather station several hundred meters from the Xiaoqushan seafloor observatory. Seasurface temperature and sea-surface salinity were obtained by thermal-salinity sensors installed on floats. Wind and air temperature were measured by an anemometer and thermometer installed $60 \mathrm{~m}$ above the ground at the weather station.

\section{Background of the Xiaoqushan seafloor observatory}

\subsection{Background data}

Figure 2 presents the wind speed, sea-water temperature and sea level from April 2009 to August 2010. The east-west wind speed ( $u_{\text {wind }}$, shown by the blue line in Figure $2 \mathrm{a}$ ) was relatively low and without distinct seasonal variation whereas the north-south wind speed ( $v_{\text {wind }}$, shown by the red line in Figure 2a) was higher and the northerly wind strengthened in winter (November to the following March) and the southerly wind strengthened in summer (June to September). Sea-surface temperature (red line in Figure $2 b$ ) and near-bottom temperature (dark line in Figure 2b) had the same variational trend without large discrepancy. Seasonal variation was distinguishable from the time series of temperature. The mean value of sea-surface temperature was $24.0^{\circ} \mathrm{C}$ in summer and $8.9^{\circ} \mathrm{C}$ in winter. The mean value of the near-bottom temperature was $23.3^{\circ} \mathrm{C}$ in summer and $9.3^{\circ} \mathrm{C}$ in winter. The sea level varied with neap-spring and flood-ebb periods (Figure 2c). The daily tidal range varied owing to the inequality of mixed semidiurnal tides, which are characterized as having one of a higher high tide, lower low tide, lower high tide or higher low tide. The largest tidal range was $3.5 \mathrm{~m}$ during the spring tide and the smallest tidal range was $1.5 \mathrm{~m}$ during the neap tide.

\subsection{Frequency power spectral analysis}

It is known that the combined effects of the gravitational force exerted by the Moon and Sun and the rotation of the Earth lead to motions with different periods. As a result, motions in the ocean can be decomposed into a variety of unrelated harmonic motions with different frequencies [13]; 

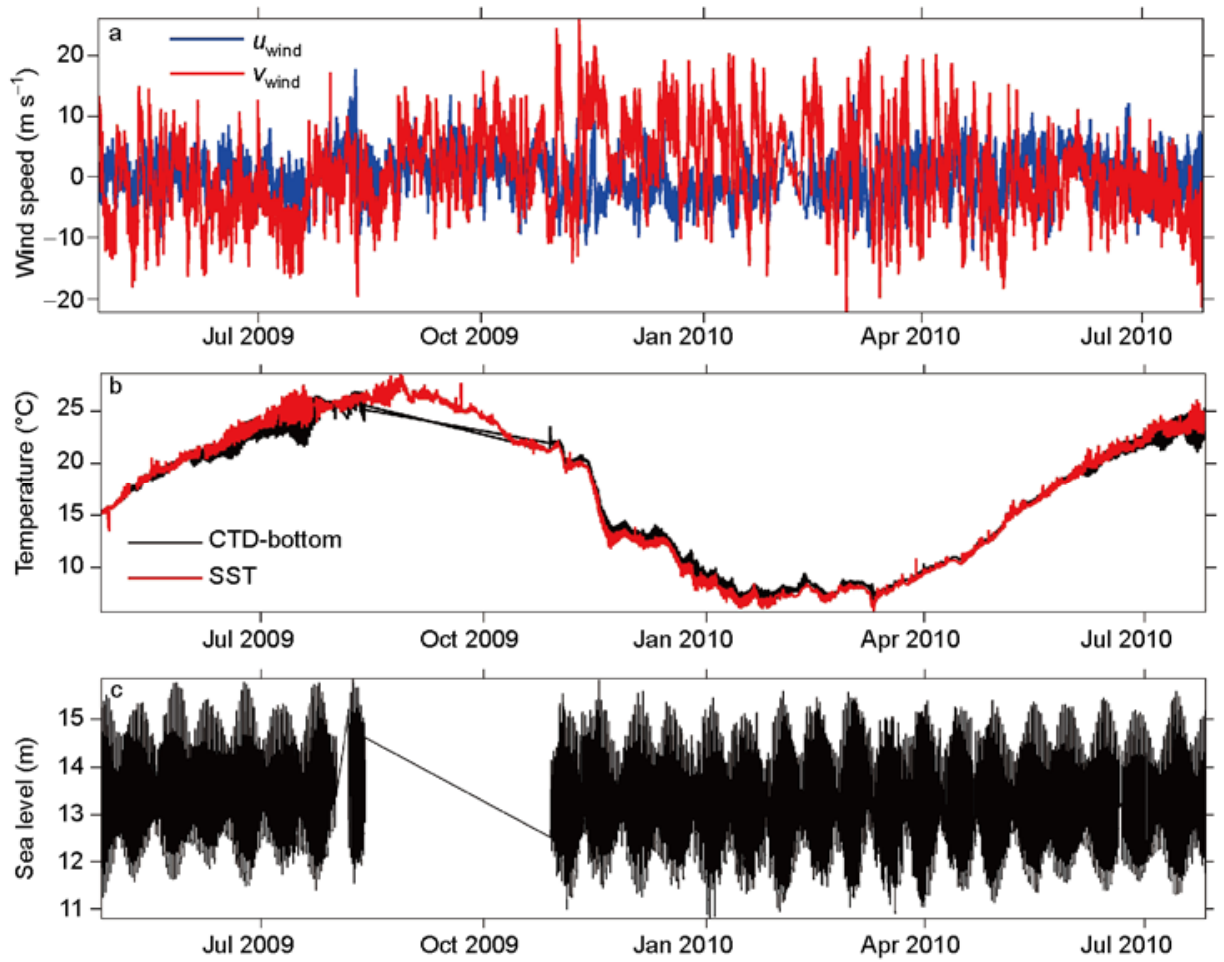

Figure 2 Measurements obtained from the Xiaoqushan seafloor observatory and weather station (from April 20, 2009 to August 31, 2010. The period of interruption was from August 13 to October 28, 2009). a, Wind speed (the blue line shows the east-west wind speed $\left(u_{\text {wind }}\right)$ and the red line shows the north-south wind speed $\left(v_{\text {wind }}\right)$ ); $\mathrm{b}$, temperature (the black line shows the near-bottom sea-water temperature and the red line shows the sea-surface temperature); c, sea level.

that is,

$$
x(t)=\sum_{i=1}^{N}\left(\alpha_{i} \cos \omega_{i} t+\beta_{i} \sin \omega_{i} t\right)
$$

where $x(t)$ is the time series of any ocean variable, $\alpha$ and $\beta$ are amplitudes, $\omega$ is frequency, and $t$ is time. The power spectrum $(p(\omega))$ of a random signal can be estimated from a certain number of sampled data. The spectrum is defined as

$$
p(\omega)=\sum_{m=-\infty}^{+\infty} \varphi(m) \mathrm{e}^{-j \omega m} .
$$

The frequency power spectrum of a random signal is periodical and can be expanded by Fourier transformation. $\phi(m)$ is the coefficient of each harmonic component. To determine the tide types for the observed site, power spectra of the sea-water temperature and sea level (from April 20 to August 12, 2009) were calculated by fast Fourier transformation (Figure 3). Both the spectra of temperature and sea level indicate that there are distinct diurnal $\left(K_{1}\right)$ and semidiurnal $\left(M_{2}\right)$ periods. This result is consistent with results obtained in other studies [14].

\subsection{Tidal harmonic analysis}

It is notable in Figure 3 that the sea-water temperature and sea level are the results of superposition of many tidal con- stituents with different frequencies. Temperature and sea level can be decomposed according to eq. (1), and the amplitude and phase angle of each tidal constituent can be calculated using the least-squares method. This procedure is so-called tidal harmonic analysis. Tidal harmonic constants were calculated using the T-tide algorithm [15] and the tidal signals of sea level (denoted sea level-simu) were then simulated. The sea-level anomaly (sla) can be obtained by substracting the simulated sea level from the observed sea level (denoted sea level-obs). The tidal harmonic analysis for the period from April to July 2009 is shown in Figure 4. Statistically, the sea-level variation calculated through tidal harmonic analysis accounts for $98.5 \%$ of the observed sea-level variation. The covariance of the simulated sea level, observed sea level and sea-level anomaly is 0.84, 0.85 and 0.012 , respectively. These values suggest that the simulation result and observation almost match and that tidal harmonic analysis works well.

\section{Causes of the sea-level anomaly}

\subsection{Sea-level anomaly induced by local wind}

Many factors account for the sea-level anomaly including the sea-surface wind, air pressure, temperature, and topography. Sea-surface wind greatly affects sea-level variations [16]. This section focuses on the relationship between local 

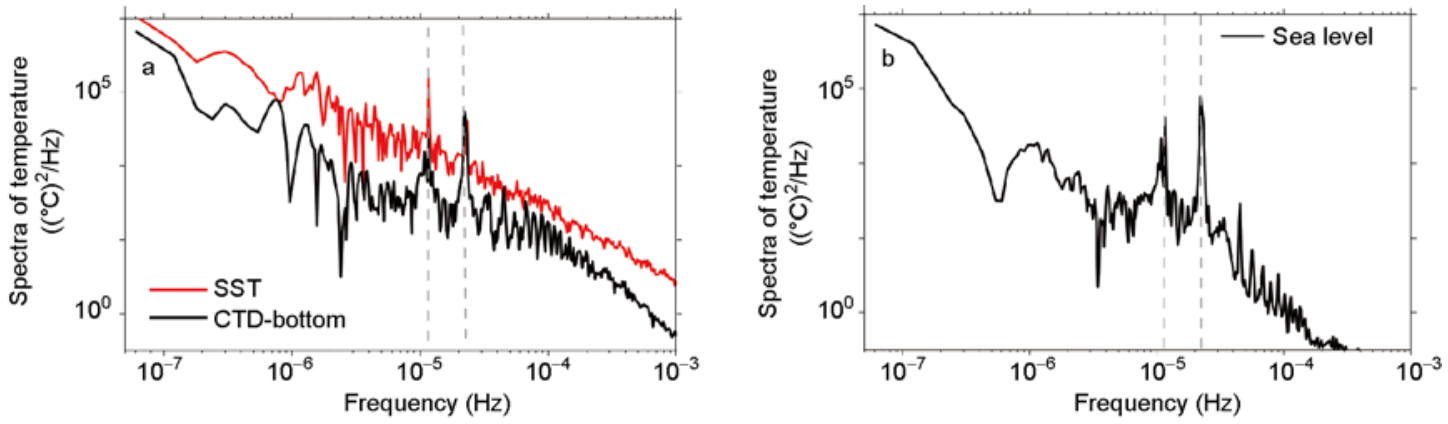

Figure 3 Spectra of temperature and sea level obtained from 20 April to 12 August, 2009. a, Sea-water temperature (the red line shows the sea surface temperature and the black line shows the near-bottom temperature); b, the power spectrum of sea level (diurnal $\left(K_{1}\right)$ and semidiurnal frequencies $\left(M_{2}\right)$ are indicated with dashed lines).
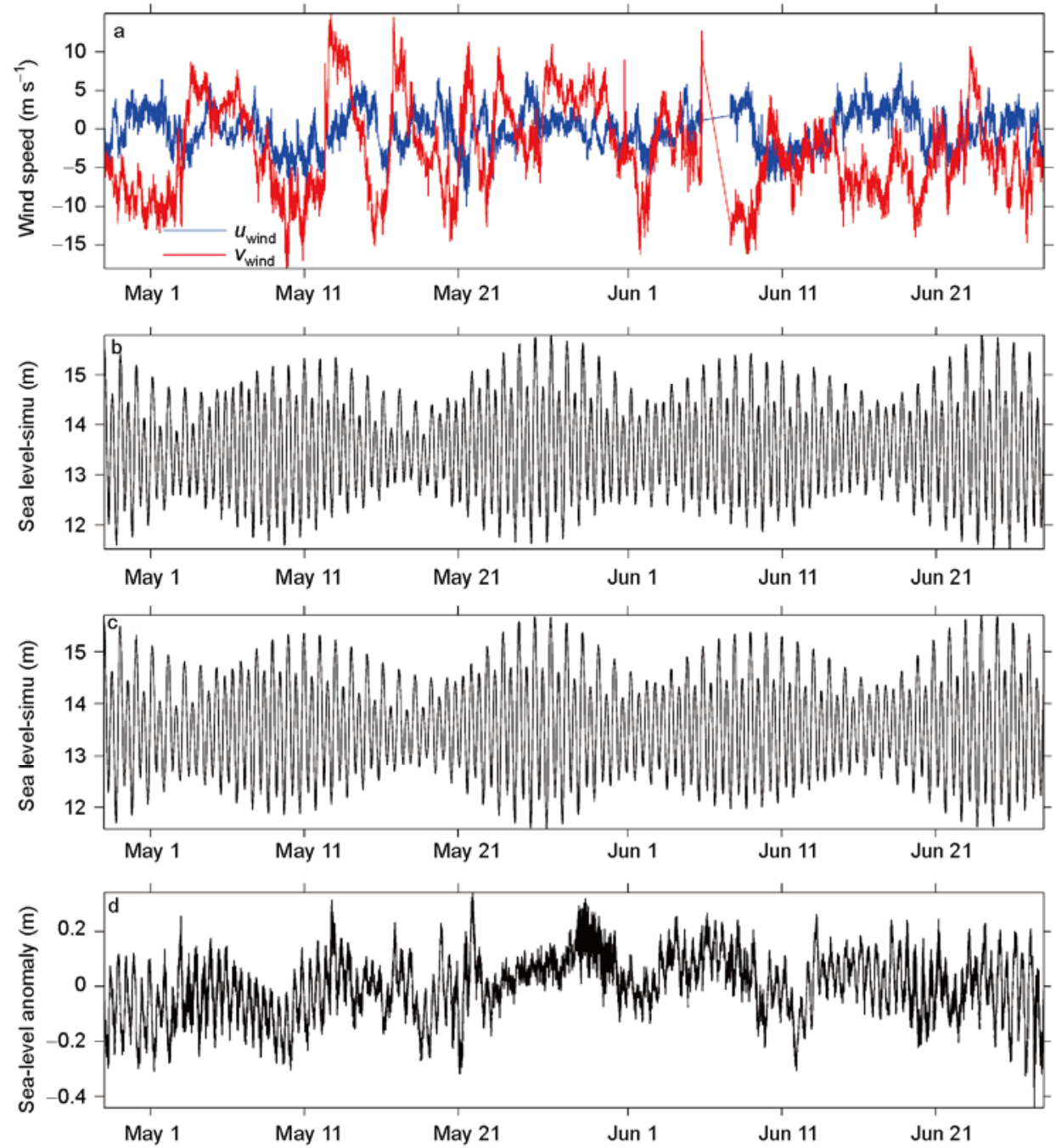

Figure 4 Time series of wind and sea level from April to July 2009. a, Wind speed (the blue line shows the east-west wind speed ( $\left.u_{\text {wind }}\right)$ and the red line shows the north-south wind speed $\left.\left(v_{\text {wind }}\right)\right)$; b, observed sea level; c, simulated sea level; d, sea-level anomaly.

wind and the sea-level anomaly.

Taking the measurements obtained from April 28 to June 27, 2009 for example (Figure 4), the coefficient of correlation between east-west wind speed $\left(u_{\text {wind }}\right)$ and sea-level anomaly is 0.21 , and the coefficient of correlation between north-south wind speed ( $\left.v_{\text {wind }}\right)$ and sea-level anomaly is and 0.30. Additionally, the coefficient of correlation between the scalar wind speed $\left(\sqrt{\left(u_{\text {wind }}\right)^{2}+\left(v_{\text {wind }}\right)^{2}}\right)$ and sla is -0.13 . These small coefficients suggest that there is no distin- 
guishable correlation between local wind and the sea-level anomaly during this period, probably because the wind at this time is relatively stable and drives only a small sea-level variation (Figure 2).

The situation greatly differs when analyzing the measurements obtained from February 9 to April 10, 2010 (Figure 5). During this period, the coefficient of correlation between $u_{\text {wind }}$ and sla is 0.07 , the coefficient of correlation between $v_{\text {wind }}$ and sla is 0.65 , the coefficient of correlation between $\sqrt{\left(u_{\text {wind }}\right)^{2}+\left(v_{\text {wind }}\right)^{2}}$ and sla is 0.17 (95\% confidence interval). That is, the correlation between the northsouth wind speed and the sea-level anomaly is large but the east-west wind had little effect on the sea-level anomaly. A possible reason for this is that the ocean off Xiaoqushan is more open in a north-south direction whereas nearby islands block east-west winds. Moreover, the mean north-south wind speed was about three times the mean east-west wind during this period. Therefore, only the north-south wind was considered in calculating the sea-level anomaly induced by wind.

The linear relationship between north-south wind speed and the sea-level anomaly was fitted using the least-squares method (Figure 6):

$$
\text { sla }_{\text {wind }}=0.14 v_{\text {wind }}-0.003 \text {, }
$$

where sla $_{\text {wind }}$ is the sea-level anomaly induced by wind.

Figure $4 \mathrm{c}$ presents the wind-induced sea-level anomaly $\left(\mathrm{sla}_{\text {wind }}\right)$. sla $\mathrm{s}_{\text {wind }}$ and the sea-level anomaly obtained by subtracting the tidal signal have similar trends and the mean ratio of $\operatorname{sla}_{\text {wind }} /$ sla is 0.71 ; i.e. the sea-level variation induced by wind accounts for about $71 \%$ of the total sea-level anomaly.

\subsection{Sea-level anomaly induced by the Chilean earth-quake tsunami}

The residual sea-level anomaly computed by subtracting $\mathrm{sla}_{\text {wind }}$ from sla was not equal to zero, and it was even pretty large at certain times, suggesting that factors other than
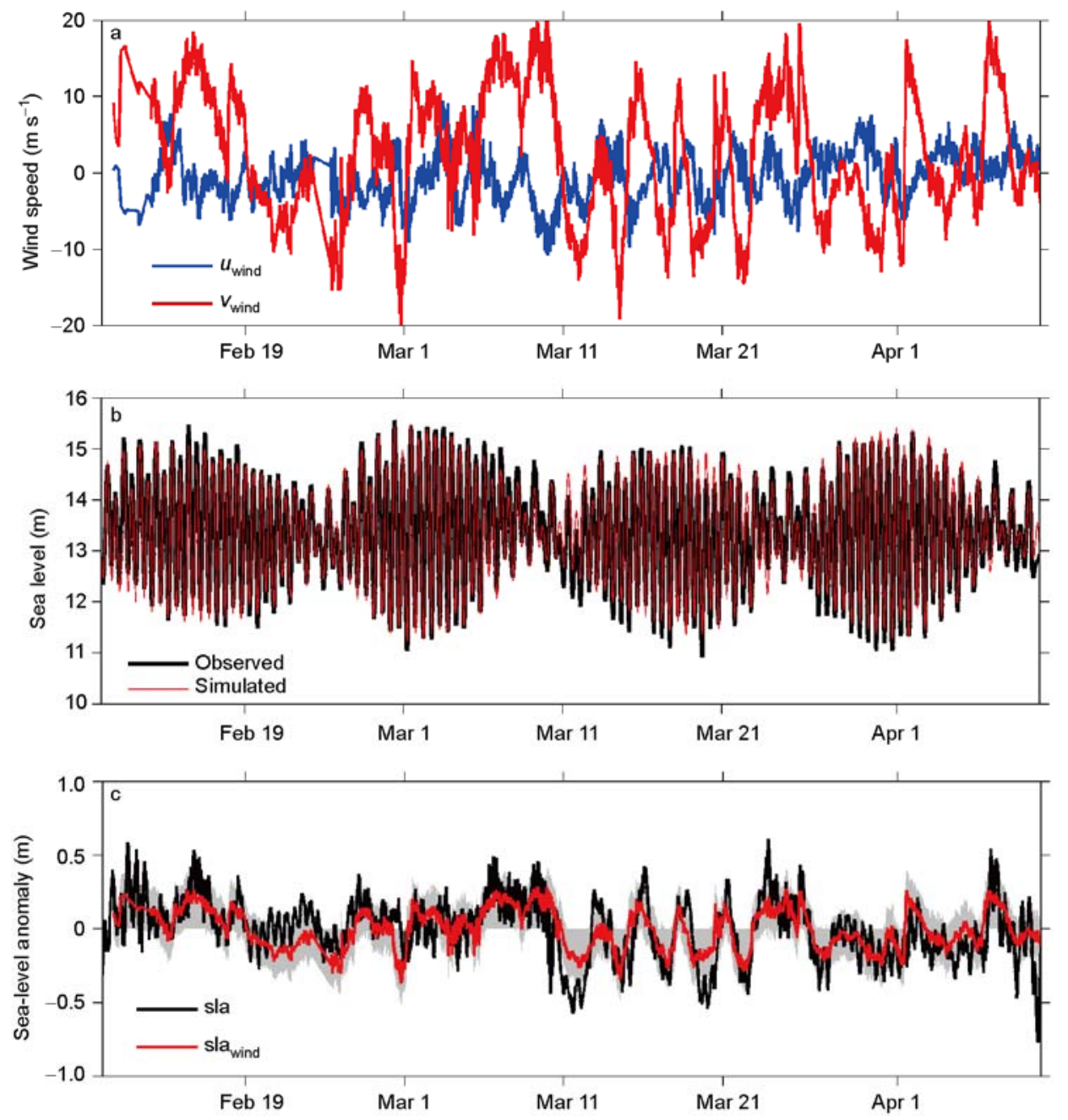

Figure 5 Time series of wind and sea level from February 9 to April 10, 2010. a, Wind speed (the blue line shows the east-west wind speed ( $u_{\text {wind }}$ ) and the red line shows the north-south wind speed $\left.\left(v_{\text {wind }}\right)\right)$; $\mathrm{b}$, the observed sea level (black line) and the sea level simulated using eq. (1) (red line); $\mathrm{c}$, sea-level anomaly (the black line shows sla and the red line shows sla $_{\text {wind }}$ calculated using eq. (3), and the gray area indicates the $95 \%$ confidence interval for sla ${ }_{\text {wind }}$ ). 


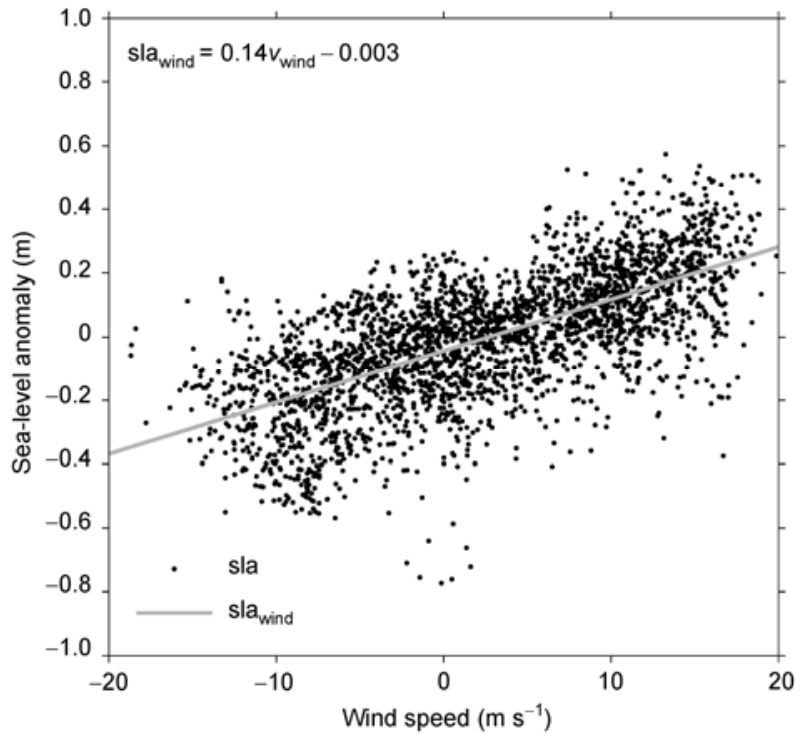

Figure 6 The fitted relationship between sla and the north-south wind speed from February 9 to April 10, 2010. Black dots show sla and the gray line is the sea-level anomaly induced by north-south wind.

local wind affected the sea-level anomaly. A tsunami induced by a large-magnitude earthquake can drive large sealevel variations. There were many earthquakes during the observation period but only the 8.8-magnitude earthquake in Chile at 14:34 on February 27, 2010 (Beijing Time) induced a tsunami, which covered all coastal areas of the Pacific Ocean except the west coast of the United States, British Columbia and Alaska [17]. According to the travel times of the Chilean tsunami (Figure 7) provided by the National Oceanic and Atmospheric Administration (NOAA), Xiaoqushan would have been affected around 15:00 on February 28.

Measurements taken at the time of the Chilean earthquake were chosen for analysis (Figure 8). It is found that the residual sea-level anomaly increased at 14:00-16:00 with values exceeding $0.3 \mathrm{~m}$. Moreover, the maximal value $(\sim 0.48 \mathrm{~m})$ appeared at around 15:00, which is consistent with the timing of the Chilean tsunami reaching the coast of China according to Figure 7 . There were no other large events recorded that could drive large sea-level changes at this time, and it is thus concluded that the large residual sealevel anomaly at 14:00-16:00 was largely caused by the Chilean tsunami propagating into the East China Sea. A far-field tsunami propagates with certain periods owing to varying coastal topography. According to the power spectrum of the residual sea-level anomaly (Figure 9) before, during and after propagation of the Chilean tsunami into the East China Sea (from 12:00 on February 27 to 12:00 on March 1, 2010), peaks appeared at frequencies corresponding to 50-150 min. This suggests that a tsunami with periods of 50-150 min contributed largely to the local sea-level anomaly around Xiaoqushan Island. This result is consistent

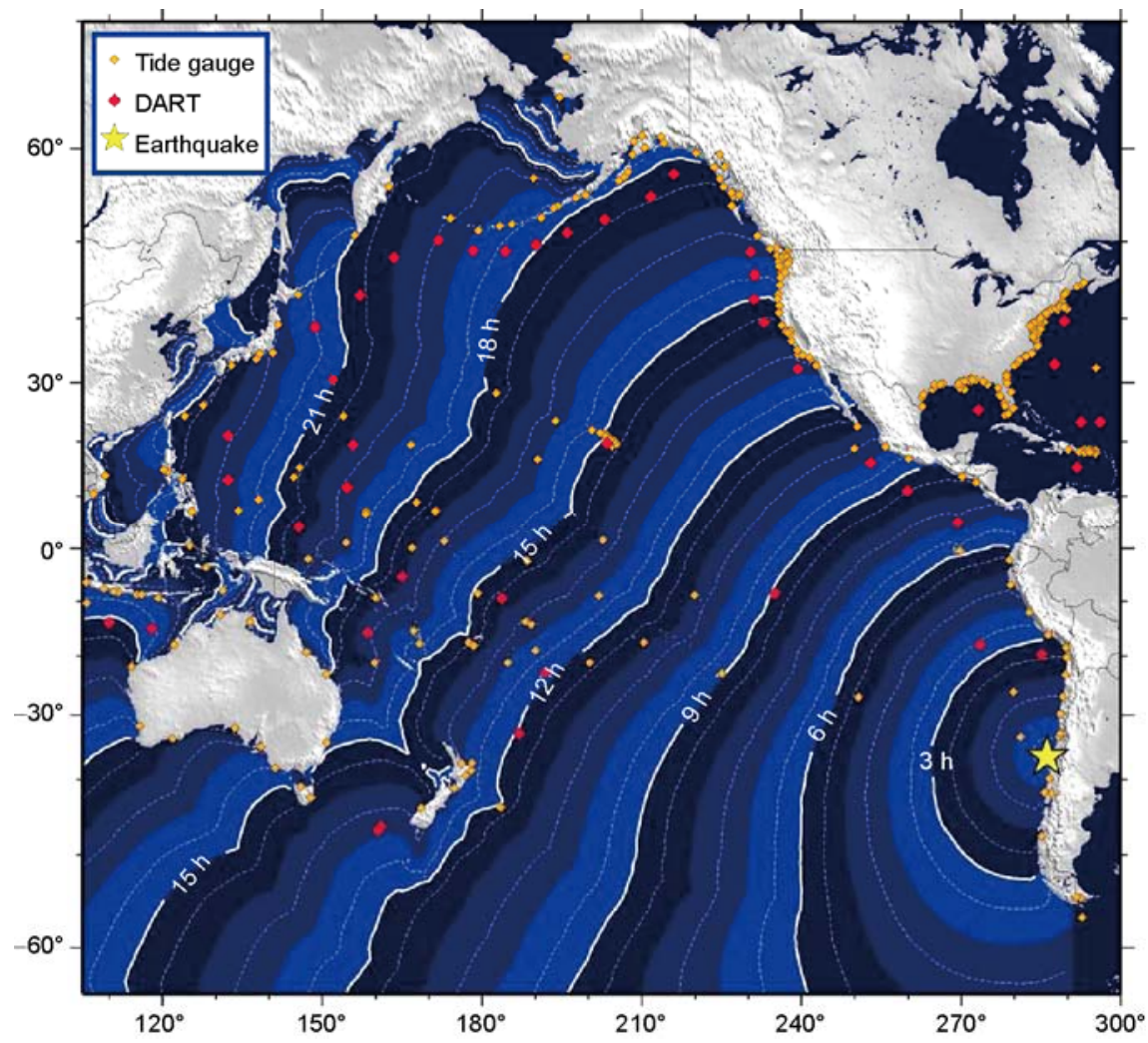

Figure 7 Travel times of the Chilean earthquake tsunami (http://wcatwc.arh.noaa.gov) simulated using a NOAA numerical model and DART (Deep-ocean Assessment and Reporting of Tsunamis) gauges. 

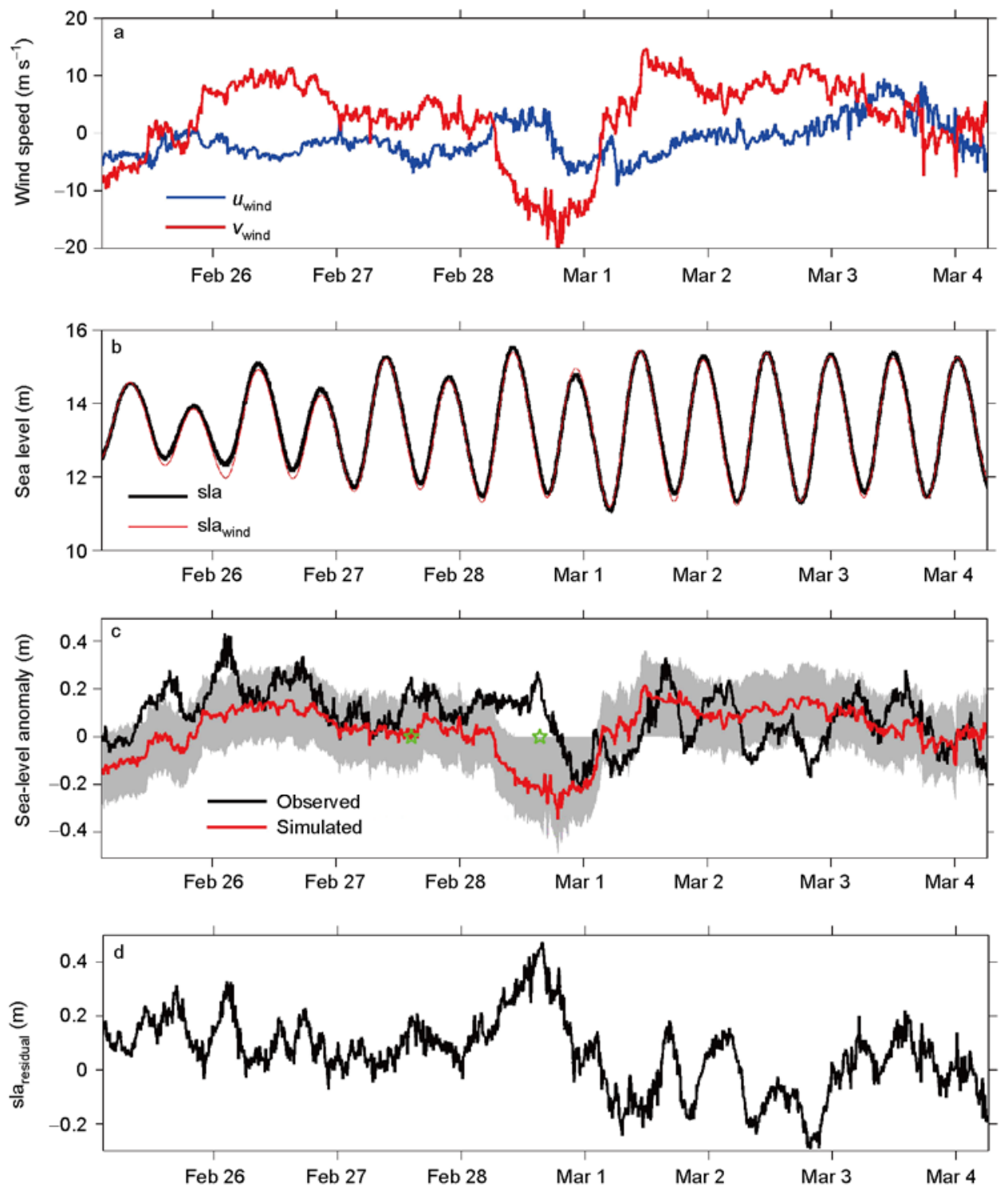

Figure 8 Measurements made at the Xiaoqushan seafloor observatory at the time of the Chilean earthquake at the end of February 2010. a, Wind speed; b, sea level (black line shows the observation data and the red line shows the tidal harmonic analysis result); c, sea-level anomaly (black line shows the result obtained by subtracting sea level-simu from sea level-obs and the red line shows sla $a_{\text {wind }}$ computed using eq. (3)), with the first pentagram indicating the time of the Chilean earthquake (14:34 on February 27, 2010) and the second indicating the arrival of the tsunami (15:00 on February 28, 2010) at the Xiaoqushan seafloor observatory; $d$, residual sea-level anomaly (sla $\mathrm{a}_{\text {residual }}$ ) obtained by subtracting sla $\mathrm{wind}_{\text {from sla. }}$
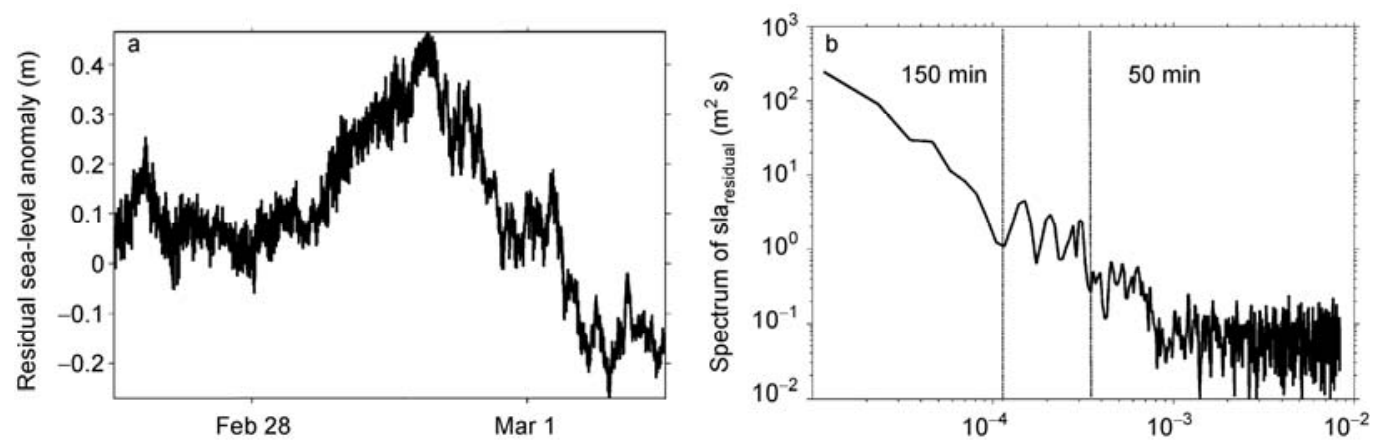

Figure 9 a, Residual sea-level anomaly before, during and after propagation of the Chilean tsunami into the East China Sea in 2010 (from 12:00 on February 27 to 12:00 on March 1); b, the power spectrum of the residual sea-level anomaly shown in a with the range of tsunami periods indicated. 
with the result of $\mathrm{Yu}$ et al. [9] that the Chilean tsunami propagating into the East China Sea had periods of 35-100 $\mathrm{min}$. The large values in the spectrum at low frequencies are probably due to background signals, such as signals of surges or wind waves propagating from other seas, not being filtered out.

\section{Discussion and conclusion}

The Xiaoqushan seafloor observatory has been running continuously for two years at the time of writing in April 2011. The oceanic and atmospheric characteristics of Xiaoqushan were analyzed using continuous data obtained from the Xiaoqushan seafloor observatory and a weather station. The results suggest that the wind and sea-water temperature (both from the sea surface and near the seafloor) vary with distinguishable seasonal periodicity. Periodic variations such as flood-ebb and spring-neap tides are seen in the sea-level time series. The observed sea level caused by tides was simulated by tidal harmonic analysis, and the simulation result accounted for $98.5 \%$ of the observed variation.

This paper focuses on the sea-level anomaly. First, the total sea-level anomaly was calculated by subtracting the harmonic analysis result from the observed sea level. Owing to the barrier formed by the surrounding islands, the effect of the north-south wind on the region near Xiaoqushan Island was greater than that of the east-west wind. The coefficient of correlation between the north-south wind and sealevel anomaly is about 0.65 when the north-south wind was stronger than the east-west wind. The linear relation between the north-south wind and sea-level anomaly was fitted using the least-squares method (eq. (3)), and the sealevel anomaly induced by wind $\mathrm{sla}_{\text {wind }}$ was then calculated using this relation.

The residual sea-level anomaly $\left(\mathrm{sla}_{\mathrm{residual}}\right)$ is the difference between sla and $\mathrm{sla}_{\text {wind }}$. The timing of the maximal sla $_{\text {residual }}$ of $0.48 \mathrm{~m}$ was consistent with the timing of the Chilean tsunami reaching Xiaoqushan Island in the ECS as forecast by the NOAA. Therefore, the Chilean tsunami propagating into the ECS was the main reason for the increase in sla residual $_{\text {at }}$ 14:00-16:00 on February 28, 2010. It is noted that the maximum value of $0.48 \mathrm{~m}$ includes signals other than that of the Chilean tsunami. Therefore, the exact sea-level anomaly induced by the Chilean tsunami is difficult to calculate. $\mathrm{Yu}$ et al. [9] found that the sea-level anomaly induced by the Chilean tsunami near Xiaoqushan Island was around $0.1 \mathrm{~m}$, which differs from the value of $0.48 \mathrm{~m}$ determined in this paper. The difference is understandable in that the different measurements were obtained at different locations with different topography and analyzed using different methods. However, the timing of the Chilean tsunami propagating into the East China Sea stated by $\mathrm{Yu}$ et al. is quite different from the timing determined in this work. According to the tsunami travel times provided by the NOAA and $\mathrm{Yu}$ et al., the tsunami propagated into the East China Sea around 14:00-16:00 on February 28, 2010, and this time was validated by measurements taken along the Japan coastline [9]. Therefore, the time that the tsunami reached Xiaoqushan Island according to our result $(\sim 15: 00$ on February 28) was close to other reported work. However, $\mathrm{Yu}$ et al. [9] argued that the tsunami reached Sheshan, Shengshan and Shenjiamen (three stations close to Xiaoqushan Island) around 20:10-20:55 on February 28, around $5 \mathrm{~h}$ later than our result. Moreover, Shengshan and Shenjiamen were supposed to observe the tsunami signal earlier than Sheshan according to their locations, but this was not the case in the results of Yu et al. [9]. Additionally, in the work of Yu et al. [9], the tsunami reached Lvsi station around 23:20, more than $3 \mathrm{~h}$ later than it reached Sheshan even though Lvsi is only $100 \mathrm{~km}$ from Sheshan. This is difficult to understand considering the average tsunami propagation speed was about $700 \mathrm{~km} / \mathrm{h}$ [9]. From the present measurements and results, it is notable that the far-field propagation into coastal seas is quite complicate. The methods for calculating the sea-level anomaly induced by a tsunami need further calibration. In any event, the records for the Chilean tsunami obtained by the Xiaoqushan seafloor observatory are useful in designing a tsunami warning system.

Comments and suggestions made by Prof. Pinxian Wang were invaluable. We appreciate help provided by colleagues involved in the engineering and data collection of the Xiaoqushan seafloor observatory, and Maoxun Gong and Tongjun Li from the East China Sea Bureau of State Oceanic Administration for providing data recorded by the weather station. This work was supported by Shanghai Committee of Science and Technology (06DZ12012), State Key Lab of Marine Geology (MG200907 and MG200910), Shanghai Municipal Natural Science Foundation (11ZR1438800) and the Program for Young Excellent Talents in Tongji University (2009KJ045).

1 Yang J, Sha W Y, Lu J Z, et al. The characteristics of sea level anomaly in China coastal seas (in Chinese). Mar Forecasts, 2004, 21 : 29-36

2 Zheng D W, Ding X L, Zhou Y H, et al. Premonitory phenomenon El Niño and event reftected in the observations sea level. Chinese Sci Bull, 2000, 45: 2231-2236

3 Carayannis G P. The earthquake and tsunami of 27 February 2010 in Chile-Evaluation of source mechanism and of near and far-field tsunami effects. Sci Tsunami Hazards, 2010, 29: 96-126

4 Voit S S. Tsunamis. Ann Rev Fluid Mech, 1987, 19: 217-236

5 Chen Y, Chen Q F. Indonesian tsunami and the related geophysical phenomena (in Chinese). Prog Geophys, 2005, 20: 112-117

6 Yang M L. The current status and progress of earthquake induced tsunami warning system (in Chinese). South China J Seismol, 2005, 25: 22-29

7 Huang Y L, Gao J S. Surges induced by tsunami along Su-Zhe-Hu coasts (in Chinese). J Disaster Prevent Mitigat Eng, 2008, 28: 177-183

8 Wen R Z, Ren Y F, Zhou Z H, et al. Numerical simulation of the farfiled tsunami (in Chinese). Earthq Eng Eng Vibrat, 2008, 28: 28-34

9 Yu F J, Yuan Y, Zhao L D, et al. Evaluation of potential hazards from teletsunami in China: Tidal observations of a teletsunami generated by the Chile $8.8 M_{\mathrm{w}}$ earthquake. Chinese Sci Bull, 2011, 56: 1108-1116

10 Lay T, Kanamori H, Ammon C, et al. The great Sumatra-Andaman 
earthquake of 26 December 2004. Science, 2005, 308: 1127-1133

11 Godin O A, V G Irisov, Leben R R, et al. Variation in sea surface roughness induced by the 2004 Sumatra-Andaman tsunami. Nat Hazards Earth Syst Sci, 2009, 9: 1135-1147

12 Xu H P, Zhang Y W, Xu C W, et al. Coastal seafloor observatory at Xiaoqushan in the East China Sea. Chinese Sci Bull, 2011, 56: 2839-2845

13 Fang G H, Zheng W Z, Chen Z Y, et al. The Analysis and Forecasting for Tides and Tidal Current (in Chinese). Beijing: Ocean Press, 1986

14 Du Y, Qi Y Q, Chen J, et al. Analysis on the continuous current measurements obtained from the East China Sea (in Chinese). Ocean Eng, 2003, 21: 95-100

15 Pawlowicz R, Beardsley B, Lentz S. Classical tidal harmonic analysis including error estimates in MATLAB using T_TIDE. Comp Geosc, 2002, 28: 929-937

16 Hinata H, Kanatsu N, Fujii S. Dependence of wind-driven current on wind stress direction in a small semienclosed, homogeneous rotating basin. J Phys Oceanogr, 2010, 40: 1488-1500

17 Michelini A, Lauciani V, Selvaggi G. The 2010 Chile Earthquake: Rapid assessments of tsunami. Eos Trans AGU, 2010, 91: 305

Open Access This article is distributed under the terms of the Creative Commons Attribution License which permits any use, distribution, and reproduction in any medium, provided the original author(s) and source are credited. 